\title{
Experimental Comparison Study on Cyclic Behavior of Coupled Shear Walls with Steel and RC Coupling Beam
}

\author{
Mengde Panga, Guoqiang Lia,b*, Feifei Suna ,Liulian $\mathrm{Li}^{\mathrm{c}}$ and Jianyun Sun${ }^{\mathrm{c}}$ \\ ${ }^{a}$ College of Civil Engineering, Tongji University, Shanghai 200092, China \\ b State Key Laboratory for Disaster Reduction in Civil Engineering, Tongji University, Shanghai, China \\ ${ }^{\mathrm{c}}$ China State Construction Technical Centre, Beijing, 101320, China \\ *corresponding author, e-mail address: gqli@tongji.edu.cn
}

\begin{abstract}
Coupled shear walls are widely used in high rise buildings, since they can not only provide efficient lateral stiffness but also behave outstanding energy dissipation ability especially for earthquake-resistance. Traditionally, the coupling beams are made of reinforced concrete, which are prone to shear failure due to low aspect ratio and greatly reduce the efficiency and ability of energy dissipation. For overcoming the shortcoming of concrete reinforced coupling beams (RCB), an innovative steel coupling beams called two-levelyielding steel coupling beam (TYSCB) is invented to balance the demand of stiffness and energy dissipation for coupled shear walls. TYSCBs are made of two parallel steel beams with yielding at two different levels. To verify and investigate the aseismic behaviour improvement of TYSCB-coupled shear walls, two $1 / 3$ scale, 10 -storey coupled shear wall specimens with TYSCB and RCB were tested under both gravity and lateral displacement reversals. These two specimens were designed with the same initial lateral stiffness, thus to be easier to compare. The experimental TYSCB specimen demonstrated more robust cyclic performance. Both specimens reached $1.75 \%$ lateral drift, however, the TYSCBcoupled shear wall showed minimal strength degradation and higher bearing capacity. Additionally, a larger amount of energy was dissipated during each test of the TYSCB specimen, compared with the RCB specimen. Based on the experimental results, design recommendations are provided.
\end{abstract}

Keywords: experimental comparison study; two-level yielding steel coupling beam; einforced concrete coupling beam; cyclic behaviour.

\section{Introduction}

Coupled shear walls have provided a suitable solution for lateral load resisting systems in tall buildings[1-3]. The overall stiffness and damping in these structures are strongly influenced by the mechanical and structural properties of not only the walls but also the coupling beams. Traditional reinforced concrete coupling beams are prone to shear failure due to a large aspect ratio. This shear failure, as a brittle failure, cannot satisfy the high ductility demand of coupling beams. As an alternative, steel coupling beams (SCB) are preferred owing to their excellent capacity of plastic deformation and energy dissipation. With the application of SCBs, traditional coupled shear wall systems turn to be hybrid coupled wall systems (HCW).[4]

Recently an innovative steel coupling beam called two-level-yielding steel coupling beam (TYSCB) was proposed by $\mathrm{Li}$ et $\mathrm{al}[5,6]$. It consists of two components: shear-yielding beam and bending-yielding beam, as shown in Fig. 1. The shear-yielding beam (Fig. 1(a)) is designed to yield at minor earthquakes and the bending-yielding beam (Fig. 1(b)) is to yield at design earthquakes. These two components work independently. Under a minor earthquake, when the shear yielding beam yields, the bending-yielding beam is still in elastic. In this way, the coupling beam may dissipate energy by the yielding of the shear-yielding beam, and at the same time ensures that its stiffness is 
maintained by the elastic bending-yielding beam. The proposed steel coupling beam is to provide sufficient lateral stiffness and energy absorption for the whole coupled shear wall structure. The experimental results showed that TYSCB can dissipate energy under a small earthquake. However, at the same time, its stiffness will not deteriorate too fast. When subjected to a major earthquake, TYSCB could perform better energy-dissipation ability than SCBs.

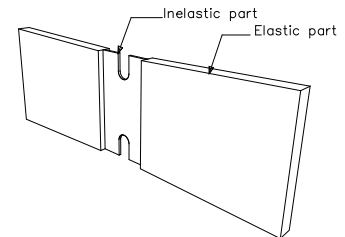

(a) Shear yielding beam

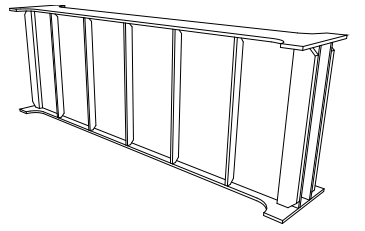

(b) Bend-yielding beam

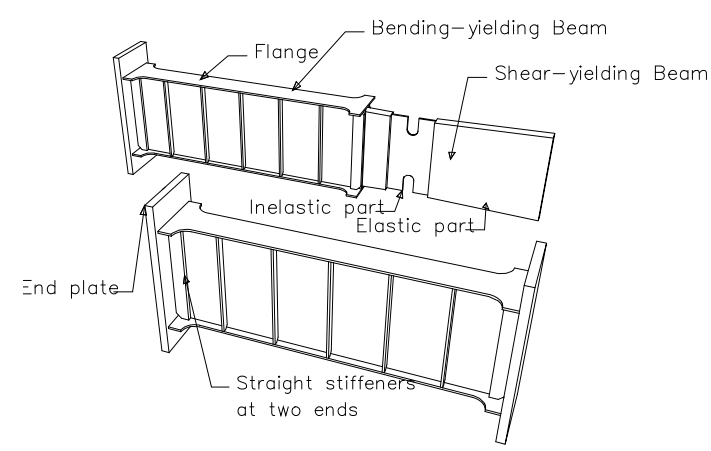

(c) 3-D view of TYSCB

Fig. 1 Configuration of TYSCB

$\mathrm{Li}$ et al made a series of seismic performance comparisons of coupled shear walls with various coupling beams through numerical analysis. It was found steel coupling beams (SCBs or TYSCBs) could largely improve the energydissipation ability of coupled shear wall systems[7]. However, the corresponding experimental verification study is relatively deficient. To this end, two $1 / 3$-scale ten-storey coupled shear wall specimens were tested under both gravity and lateral displacement reversals.

Specimen CW-RC, featuring traditional reinforced concrete(RC) shear walls and RC coupling beams, was designed with the same initial stiffness with Specimen CW-TYSCB, which was featuring $\mathrm{RC}$ shear walls and twolevel-yielding steel coupling beam.

The wall piers of the two specimens shared the same geometric size and reinforcement configuration. Two full-length $\mathrm{H}$-section $(100 \times 100 \times 6 \times 8)$ structural steels were set as the boundary elements for each wall pier.
The objectives of this research aim to (1) investigate the cyclic behavior of RC and hybrid coupled shear wall syetems that features longitudinally reinforced and two-level-yielding steel coupling beam, respectively; and (2) evluate the performance of using two $\mathrm{H}$-section steel boundary elements for each wall pier.

\section{Test specimens}

Test specimens were designed to represent a $1 / 3$-scale ten-storey coupled shear wall system. The total height of the specimens was $10 \mathrm{~m}$, and each storey has the same height of $0.8 \mathrm{~m}$. The width of wall piers was $160 \mathrm{~mm}$. The clear length to height ratio, also known as aspect ratio, of the $\mathrm{RC}$ and the two-level-yielding steel coupling beam are approximately 2.3 and 2.6, respectively. The specimen was designed to achieve the mechanism in which yielding is assumed to develop over the coupling beams and at bases of the walls. The detailed configuration of the two specimens was shown in Fig. 2.

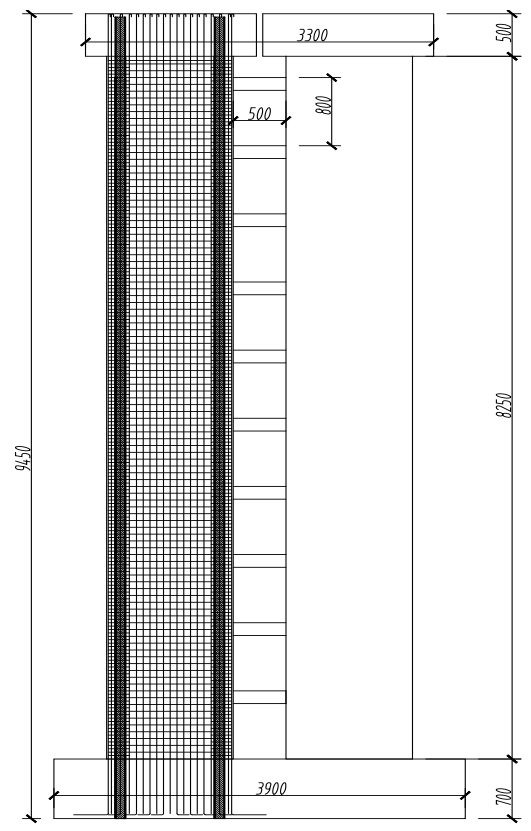

(a) Configuration of the whole specimen

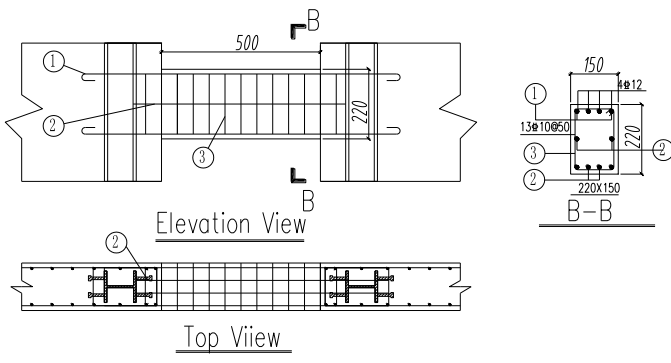

(b) RC-Coupling beam 


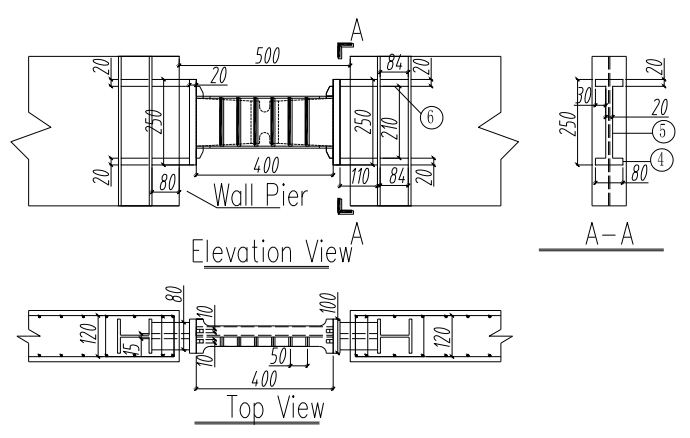

(c) TYSCB-Coupling beam

Fig. 2 Configuration of two specimens

\section{1. $R C$ coupling beam}

The RC coupling beam is $500 \mathrm{~mm}$ long, 220 $\mathrm{mm}$ high and $160 \mathrm{~mm}$ wide. Four HRB400 (i.e. the nominal yielding strength $=400 \mathrm{MPa}$ ) rebars with a diameter of $12 \mathrm{~mm}$ were placed at the top and bottom, recpectively. Thirteen reinforcing bars of $\$ 10 @ 50 \mathrm{~mm}$ (in a diameter of $10 \mathrm{~mm}$ and spacing of $50 \mathrm{~mm}$ ) were arranged as stirrups along the length direction of RC coupling beams. The detailed reinforcement layout of the $\mathrm{RC}$ coupling beam is presented in Fig. 2(a).

The initial stiffness of RC coupling beam is calculated as $180 \mathrm{kN} / \mathrm{mm}$, with a stiffness reduction coefficient of 0.7 considered.

\subsection{Two-level-yielding steel coupling beam}

The TYSCB was designed based on the approach proposed by Li et al. The low yield point (LYP) steel LYP 225 (the nominal yield strength was $225 \mathrm{MPa}$ ) was used to made up of the inelastic part of the shear-yielding beam of TYSCB. The length of TYSCB is $400 \mathrm{~mm}$, and the height is $150 \mathrm{~mm}$. To keep the same initial stiffness with RC coupling beam, the first yielding level of TYSCB is designed as $(0.6 \mathrm{~mm}$, $110 \mathrm{kN})$, and the second yielding level is $(1.3$ $\mathrm{mm}, 220 \mathrm{kN})$.The detailed configuration of TYSCB is shown in Fig. 2(c).

\section{3. $R C$ shear wall}

The design criteria for RC shear wall are to prevent shear failure, with satisfying the bending capacity first. The shear wall is designed based on an axial force-moment (P-M) interaction diagram. Except for the self-weight of the specimen and the experimental setups, an additional gravity load of $400 \mathrm{kN}$ which accounts for $10 \% A_{g} f_{c}^{\prime}$, was applied for each wall pier.
Two $9.41 \mathrm{~m}$ long $\mathrm{H}$-steel boundary elements at both ends of the wall pier is reinforced by a total of $4 \phi 10 \mathrm{HRB} 400$ longitudinal reinforcing bars. Two curtains of $\phi 10$ HRB400 reinforcing bars at $80 \mathrm{~mm}$ spacing are provided for shear resistance. The reinforcement layouts of $\mathrm{RC}$ shear walls in Specimen CW-RC and CWTYSCB are presented in Fig. 2(a).

\subsection{Connection detailings of both specimens}

For specimen $\mathrm{CW}-\mathrm{RC}$, the longitudinal reinforcements of coupling beams were welded to the flanges of the boundary H-steel. TYSCBs were connected to the $\mathrm{H}$-steel boundary element through a short bracket. In this way, the two Hsteels connected with the two ends of TYSCB will have two roles: embedded elements for coupling beam and boundary elements for shear wall. The design method for this 'beam-column' joint was referenced from the researches by $\mathrm{Li}$ et al $[8,9]$. The detailed configuration of the connetion is presented in Fig. 2(b) and Fig. 2(c) . This bracket configuration made it more easier to replace the TYSCBs.

\section{Test setup and test procedure}

Specimens are loaded horizontally with one $2000 \mathrm{kN}$ hydraulic actuator at the top rigid beam. A 3-D detailed illustration of the experimental setup is shown in Fig. 3. The whole loading procedure was displacement controlled and the detailed loading history inshown in Fig. 4. This setup provided an approximate first-mode dominant loading profile for the test specimen. The fixed boundary condition at the bottom of the specimens was provided through a heavily reinforced concrete block which was anchored on the strong floor through twelfth $50 \mathrm{~mm}$ diameter prestressed rods. Lateral supports are provided using an steel reaction frame to prevent out-of-plane movement of the shear wall.

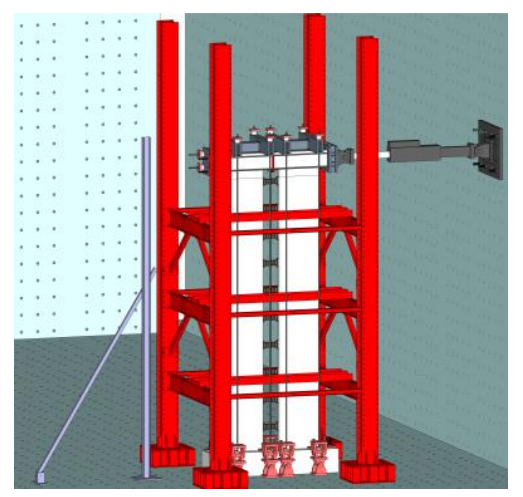

(a) 3D view of testsetup 


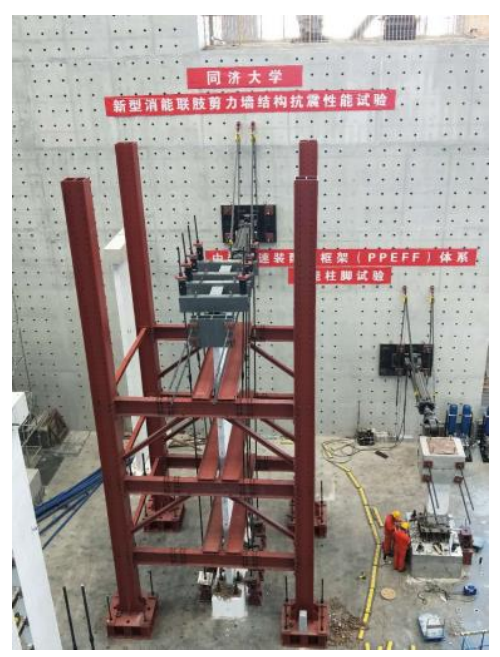

(b) test setup

Fig. 3 Test Setup

The $400 \mathrm{kN}$ additional gravity load was applied to the top of each shear wall using four hydraulic jacks which pulled four $30 \mathrm{~mm}$ prestressed rods at the same time before applying lateral displacement.

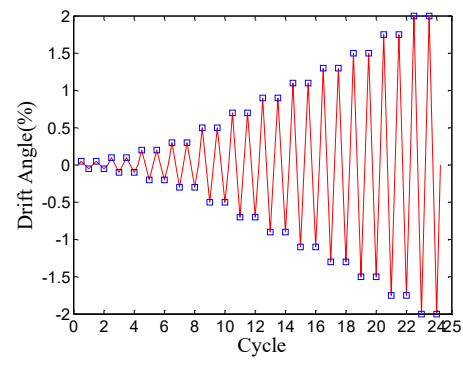

Fig. 4 Loading pattern

\section{Test results}

Hysteretic responses between the drift and the lateral force of Specimen CW-RC and CWTYSCB is presented in Fig. 5(a) and (b), respectively. It should be noted that horizontal forces due to horizontal components of the prestressed rods have been cancelled and have no effect on the total lateral force.

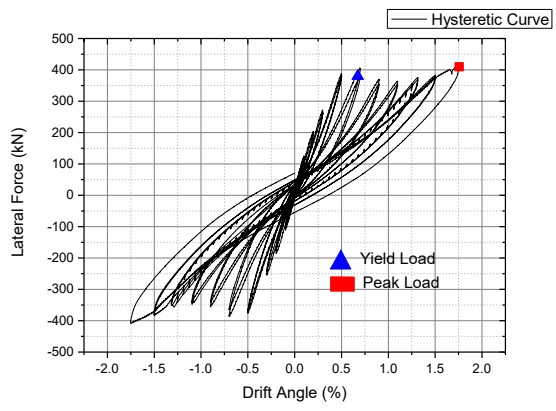

(a) $\mathrm{CW}-\mathrm{RC}$

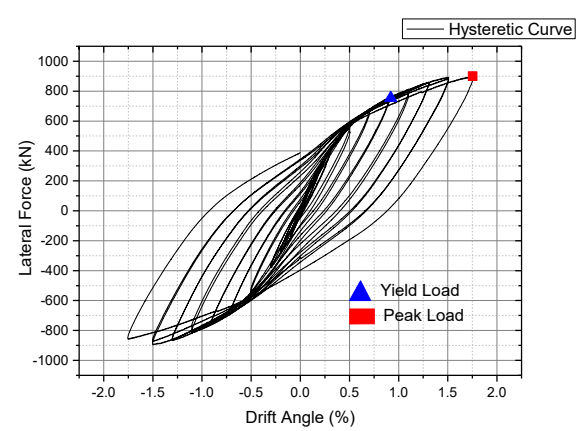

(b) CW-TYSCB

Fig. 5 Hysteretic response

The ultimate capacity of CW-RC is $420 \mathrm{kN}$, and it is about $900 \mathrm{kN}$ for Specimen CWTYSCB. The results clearly showed that using TYSCB can have a much higher bearing capacity and plumper hysteretic response.

Crack development was traced at bases of the wall piers and all the coupling beams for Specimen CW-RC, and only the wall base for Specimen CW-TYSCB. The first hairline cracks of the two specimens appeared at the same drift angle of $1 / 1000$. With the increasing of loading, the development of cracks of Specimen CWTYSCB were more rapid, since at the same loading level CW-TYSCB could bear larger lateral forces. The final state of both specimens are presented in Fig. 6.

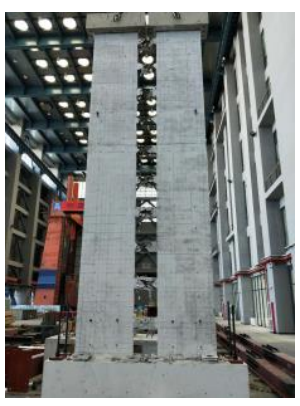

(a) CW-RC

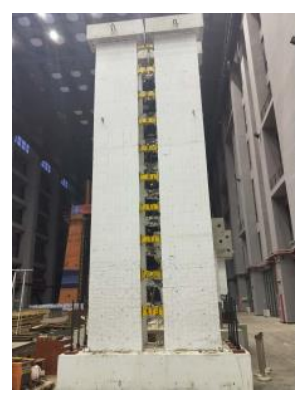

(b) CW-TYSCB
Fig. 6 Final state of the both specimens

For Specimen CW-RC, all the coupling beams were failed due to shear force, and a very significant X-shape crack could be observed on the first-floor coupling beam. The degree of destruction depended from the $10^{\text {th }}$-floor to the $1^{\text {st }}$-floor coupling beam. The roof-floor coupling beams lost a large portion of the concrete core nd some stirrup reinforcements buckled. The same situation appeared on the $6^{\text {th }}$ to $9^{\text {th }}-$ floor coupling beams, but not as significant as the roof-floor. The bases of wall piers damaged little, and the strain gauages on the flanges of the 
boundary steels showed the H-steel were still in hardening satge. This result indicated the couling beams failed before the wall base, which was also the expected failure mechanism for coupled shear wall system.

For Specimen CW-TYSCB, the $10^{\text {th }}$-floor to $4^{\text {th }}-$ floor coupling beams were damaged after completing the first loading cyle of $1.75 \%$ drift angle. The width of the crack on the wall base was more larger than that of the Specimen CWRC. However, the RC wall piers were not failure in the final stage. The preffeered energydissipation mechanism was also achieved. Furtherore, the Specimen CW-TYSCB showed better energy-dissipation ability.

The connection between TYSCB and the RC wall piers in Specimen CW-TYSCB appeared to be intact and almost elastic through the whole loading process.

\subsection{Energy dissipation}

Energy dissipation of each cycle for both specimens was evaluated through equivalent viscous damping ratio, which is determined by the energy dissipation, area enclosed by hysteretic loops, divided by $4 \pi$ times linear strain energy from origin to maximum deformation point at each cycle. The analysis results of each cycle are presented in Fig. 7. According to that figure, Specimen CW-TYSCB showed more plump and robust hysteretic response at the same drift level. It should be noted that Specimen CW-RC inidicated fairly considerable plump curve under the $1.75 \%$ drift angle cycle loading. Based on the gauage readings, this phenomena was caused by the yielding of the $\mathrm{H}$-steel boundary elements. As a result, the better energy-dissipation in Specimen-TYSCB was most attributed to the steel coupling beams.

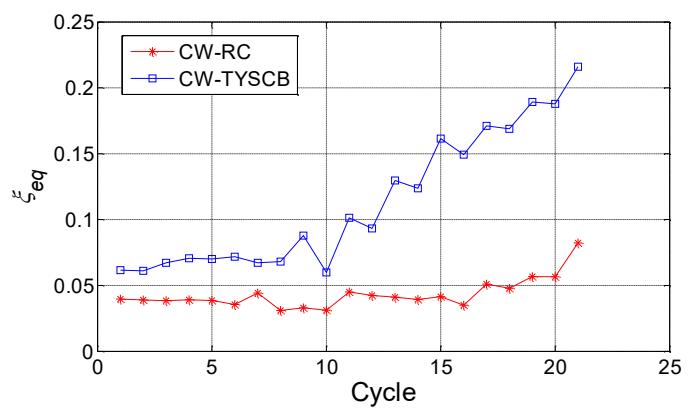

Fig. 7 Equivalent viscous damping ratio

\subsection{Stiffness and displacement ductility}

A bilinear lateral force-drift model was developed for each soecimen in order to evaluate lateral stiffness and displacement ductility. This idealized bilinear curve was developed in the following way: First, anevelope curve was created by linearly connecting the peak value of the first cycle at each target drift level in the positive direction. Second, the ultimate drift ratio, $d_{u}$ was selected as the point corresponding to the lateral force with a $20 \%$ drop from the peak. The yield point $\left(d_{y}, f_{y}\right)$ was defined based on theconcept of equal plastic energy so that the area enclosed by theidealized elastoplastic envelope curve was the same as that enclosed by the actual envelope curve. The idealized bilinear lateral force-drift responses of the two specimens are presented in Fig. 5 and the numerical values of the curves are summarized in Table 1.

Table 1. Bilinear response properties of Specimens CW-RC and CW-TYSCB

\begin{tabular}{cccc}
\hline Specimen & $\begin{array}{c}\text { Yield } \\
\text { Load(kN) }\end{array}$ & $\begin{array}{c}\text { Peak } \\
\text { Load(kN) }\end{array}$ & $\begin{array}{c}\text { Ultimate } \\
\text { drift }\end{array}$ \\
\hline CW-RC & 380.04 & 409.8 & $1.75 \%$ \\
CW- & 753.77 & 900.2 & $1.75 \%$ \\
TYSCB & & &
\end{tabular}

Stiffness deterioration at each drift cycle for both specimens is presented in Fig. 8. The stiffness ratio for the vertical axis is determined by the peak-to-peak secant stiffness at each cycle divided by the initial stiffness from the idealized curve. It shows that Specimen CW-TYSCB sustains better stiffness both in the repeated cycles at a given drift level and in between different drift levels.

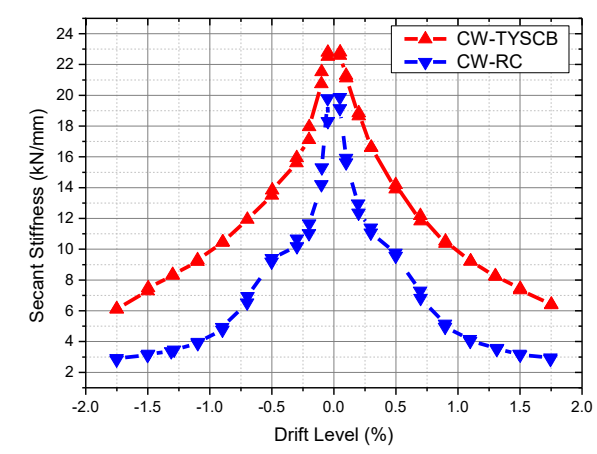

Fig. 8 Stiffness deterioration 


\section{Conclusions and recommendations}

Two $1 / 3$-scale ten-storey coupled shear wall specmens were tested in this research. Specimen-RC consisted of two RC wall piers and ten longitudinally reinforced concrete coupling beams while Specimen CW-TYSCB consisted of two RC wall piers and ten TYSCBs. Based on the experimental results, the following conclusions can be drawn:

(1) Sharing almost the same initial stiffness, the bearing capacity of Specimen CWTYSCB was two times larger than that of Specimen CW-RC. The earlier shear failure of concretes of RCBs could not guarantee the rebars develop their postyielding strength, as a result the Specimen CW-RC showed a very low bearing capacity.

(2) At the same drift level, specimen CWTYSCB suatained better lateral force in the repeated cycle, better stiffness deterioration and better energy dissipation ability.

(3) The energy dissipation ability of Specimen CW-TYSCB is far beyond that of $\mathrm{CW}-\mathrm{RC}$, and the equivalent viscous damping ratio for each loading cycle of CW-TYSCB is 2.63 times larger than CW-RC.

\section{Acknowledgements}

The work presented in this paper was supported by the Ministry of Science and Technology of China through the Thirteen Five Key Research \& Development Scheme with Grant 2016YFC0701203.

\section{References}

[1] El-Tawil S, Harries KA, Fortney PJ, Shahrooz BM, Kurama Y. Seismic Design of Hybrid Coupled Wall Systems: State of the Art. $J$ Struct Eng 2010, 136, 755-769.

[2] Harries KA, Gong B, Shahrooz BM. Behavior and Design of Reinforced Concrete, Steel, and SteeConcrete Coupling Beams. Earthq Spectra 2000, 16, 775-799.

[3] Harries KA, Mitchell D, Cook WD, Redwood RG. Seismic Response Of Steel Beams Coupling Concrete Walls. Journal of Structural Engineering 1993, 119, 3611-3629.

[4] Park W, Yun H. Seismic behaviour of coupling beams in a hybrid coupled shear walls. $J$ Constr Steel Res 2005, 61, 1492-1524.

[5] Li G, Sun F, Pang M, Liu W, Wang H. Structural Shear Wall Systems with Metal Energy Dissipation Mechanism. International Journal of High-rise Buildings 2016, 5, 195-203.

[6] Mengde Pang GLFS. Seismic Behaviour Improvement of Coupled Shear walls using Innovative Steel coupling Beams .Proceeedings of the 11th pacific structural steel conference, Shanghai, China 29-31 October, 2016.

[7] Li G, Pang M, Sun F, Jiang J, Hu D. Seismic Behavior Of Coupled Shear Wall Structures With Various Concrete And Steel Coupling Beams. The Structural Design Of Tall And Special Buildings 2017.

[8] Li G, Gu F, Jiang J, Sun F, Cyclic behavior of steel beam-concrete wall connections with embedded steel columns (I): Experimental study. Steel Compos Struct 2017, 23, 399-408.

[9] Li G, Gu F, Jiang J, Sun F. Cyclic behavior of steel beam-concrete wall connections with embedded steel columns (II): Theoretical study. Steel Compos Struct 2017, 23, 409-420. 